DOI: https://doi.org/10.32839/2304-5809/2020-12-88-15

удК 811

Мирзоева Г.А.

Институт языкознания имени И. Насими

Национальной академии наук Азербайджана

\title{
АНГЛИЙСКИЕ ЗАИМСТВОВАНИЯ В ТЮРКСКИХ ЯЗЫКАХ
}

\begin{abstract}
Аннотация. В данной статье рассматривается процесс заимствование английских слов тюркскими языками. Обзор материалов исследования показывает недостаток работ в отечественной лингвистике в комплексе, исследующем семантические и прагматические аспекты английских лексем в тюркских языках. Все вышесказанное позволяет определить актуальность темы и необходимость ее научного осмысления. Теоретико-методологической основой исследования являются работы современных лингвистов по общей и тюркской лингвистике, по теории терминов и заимствований, по социолингвистике, подготовленные с использованием материалов о языках различных систем. Подводя итоги в конце исследования отмечается, что англицизмы в современных тюркских языках, в основном, охватывает научную-техническую терминологию, что связано с большим прорывом в сфере информационных технологий.
\end{abstract}

Ключевые слова: англицизмы, заимствованные слова, тюркские языки, терминология, лингвистика.

Mirzayeva Gunel Amirkhan kyzy Linguistics Institute named after I. Nasimi of Azerbaijan National Academy of Sciences

\section{ENGLISH BORROWINGS IN TURKIC LANGUAGES}

Summary. This article examines the process of borrowing English words by Turkic languages. In theory, any language can include an unlimited number of borrowing words. The accumulation of new linguistic facts, their systemic consideration from the perspective of semantics and pragmatics allows us to identify the main borrowing tendencies, contributes to a deeper understanding of the intra-linguistic processes underlying the mechanism of word borrowing, and the development of the lexical system of borrowings in Turkic languages as a whole. The review of the research materials shows the lack of works in Russian linguistics in a complex that studies the semantic and pragmatic aspects of English lexemes in Turkic languages. The relevance of the presented work is due to the active participation of foreign languages in all major linguistic processes observed in modern Turkic languages, and the importance of studying these processes to understand the development trends. All of the above allows you to determine the relevance of the topic and the need for its scientific understanding. Borrowed English words in Turkic languages are used in accordance with phonetic, lexical, grammatical norms, either completely or partially. The theoretical and methodological basis of the study is the work of modern linguists on general and Turkic linguistics, on the theory of terms and borrowings, on sociolinguistics, prepared using materials about the languages of various systems. Summing up, the end of the study, it is noted that English borrowings in modern Turkic languages mainly cover scientific and technical terminology, which is associated with a big breakthrough in the field of information technology. In the Azerbaijani, Tatar and other Turkic languages, which were in close contact with the Russian language, until the end of the 20th century, English lexical units were borrowed through the Russian language. Scientific terminology, which lies almost entirely outside the main fund of the Turkish language, is very permeable in relation to foreign language borrowings, and most of it is maiden form terms of foreign origin.

Keywords: English borrowings, borrowing words, Turkic languages, terminology, linguistics.

$\Pi^{\circ}$ остановка проблемы. Теоретически любой язык может включать неограниченное количество заимствований. Однако язык - это система, в которой определенные законы, ограничивающие его наполнение другими элементами и постоянные контакты с иностранными партнерами и вовлеченность тюркоязычных стран в глобализацию, способствуют распространению этих слов.

Актуальность представленной работы обусловлена активным участием иноязычных слов во всех основных языковых процессах, наблюдаемых в современных тюркских языках, и важностью изучения этих процессов для понимания тенденций развития современных языков.

Прагматика и семантика противопоставлены друг другу как наука, которая занимается изменением значения слова в процессе его функционирования, с одной стороны, и как наука о значении слова, с другой стороны. Таким образом, резюмируют авторы, с позиции «словарного ви- дения» семантическое знание автономно от других видов знаний» [9, с. 209].

Как отмечал известный голландский лингвист, С. Левинсон: «Прагматика исследует аспекты, не охваченные семантической теорией ценности» [12, с. 15], его коллега, известный специалист в области прагматики ван Дийк пишет: «В качестве прагматики входит определение систем описания языковой формы, значения и деятельности» [13, с. 65].

По результатам исследований лингвиста Дж. Уотермана можно найти такие интересные фракты о взаимодействии и взаимопроникновении различных культур и языков: «Самый распространенный способ влияния языков друг на друга - это обмен словами» [14, с. 4].

Согласно теории "языковых контактов», шведский лингвист Л. Йххансон внес значительный вклад в исследование заимствованных слов в лексическом фонде тюркских языков. Рамки его научных исследований не ограничивались одним 
из тюркских языков. Изучая историю развития лексического фонда всех тюркских языков, он предложил концепцию «Модель кодирования». Модель копирования кода, разработанная Ларсом Йохансоном, использовалась для описания и объяснения эфрфектов языкового контакта в различных условиях, но с предвзятостью для настроек, связанных с тюркским языком. Понятно, что привлекательность должна быть относительным понятием в том смысле, что вещи привлекательны в данной ситуации контакта с данной парой языков в данной социолингвистической среде, а не в абсолютном смысле [11, с. 326].

Исходя из этой точки зрения, можно утверждать, что заимствованные английские слова в тюркских языках используются в соответствии с фронетическими, лексическими, грамматическими нормами либо полностью, либо частично.

Анализ последних исследований и публикаций. "Исследование исторических контактов английского и турецкого языков показывает, что турецкий литературный язык вплоть до 30-х гг. XX века не испытывал заметного влияния английского языка» [3, с. 137]. Но начиная с конца XX века в связи с глобализацией английского языка его влияние на другие языки стал более обширным. Данный процесс не обошел стороной, также и тюркские языки всего мира. Это проблема была освещена тюркологами с разных аспектов во многих исследованиях. В основном последние годы заимствования из английского языка тюркскими языками исследуются на основе языковых материалах СМИ. Например, Н.А. Сооронкулова (в кыргызском языке), Д.М. Шарапова (калмыцком языке), Вахрушева А.В. (в удмуртском языке), И.С. Назметдинова, Г.Р. Сынбулатова (в башкирском языке) в своих исследованиях опираются на языковые фракты, которые часто встречаются на языке информационных ресурсах.

Тюркские языки всегда были открытыми для заимствований. В последние годы с развитием английского языка тюркскими языками были заимствованы новые термины и понятия в сфере экономики, СМИ, медицины, педагогики и технологии. Исследуя причины данных заимствований Н.А. Сооронкулова отмечает, что, данные причины «различные по своему характеру - языковые, социальные, психические, эстетические и т. п., потребность в новых языковых dpopмах, потребность в расчленении понятий, в разнообразии средств и в их полноте, в краткости и ясности, в удобстве и т. д.» [6, с. 100].

Н.Я. Мамедова объясняет этот фракт, «языковой политикой духовенства, придворных кругов, законодательных органов, направленных на отделение литературного языка от народной речи» [3, с. 137].

Накопление новых языковых фрактов, их системное рассмотрение в ракурсе семантики и прагматики позволяет выявить основные тенденщии заимствований, способствует более глубокому осмыслению внутриязыковых процессов, лежащих в основе механизма заимствования слов, и развитию лексической системы заимствований в тюркских языках в целом. Кроме того, систематизация, унификкация и стандартизация английских заимствованных лексем приобретают особое значение для фоункционирования литературных норм этого языка. «В своих научных исследованиях, посвященных лексике, исследователи приходят к выводу о том, что лексика изучаемого им тюркского языка неоднородна в своем составе и необходимо разграничить её прежде всего на тюркский и заимствованный пласты» [4, с. 60].

Выделение нерешенных ранее частей общей проблемы. Языковые контакты являются одним из важнейших фракторов экстралингвистического характера, способствующих созданию на языке определенных новшеств. Практически каждый язык в диахроническом процессе испытывает влияние соседних языков. Социальное и языковое взаимодействие между различными государствами и людьми расширяет и углубляет языковые контакты. В данном процессе надо отметить и неоспоримую роль интернета и виртуального пространства, где наблюдается насыщенность английскими словами и терминами различных областей. «Важно подчеркнуть, что виртуальное пространство создает условия для устойчивого существования языков, обеспечивая реализацию их коммуникативного потенциала. Интернет позволяет удовлетворить основные потребности, стабилизирующих фрункционирование языков: мобильность (язык может использоваться в разных сдерах человеческой деятельности); транспортировка (передача и распространение информации на языке); необходимость безопасности (сохранение и защита языковых норм); воспроизводимость (возможность получить неограниченное количество текстов на языке); информативность (способность выражать и воспринимать новые знания)» [10, с. 790].

При исследовании английских заимствований надо учесть и фракт влияния виртуального пространства на сореры жизнедеятельности человечества.

Формулирование целей статьи (постановка задачи). В современной лингвистике вопросы семантики и прагматики относятся к объектам исследования функциональной лексикологии. В исследованиях западных лингвистов семантика и прагматика заимствованных лексем ориентированы на два исследовательских направления. Так, британские исследователи когнитивной лингвистики В. Эванс и М. Грин отмечают, что «согласно словарному взгляду, основным значением слова является информация, содержащаяся в его определении. И это собственно область лексической семантики» [9, с. 208]. Остальная информация, связанная со словом, носит энциклопедический характер и связана с прагматикой, которая является «областью, которую некоторые лингвисты считают внешней по отношению к собственно лингвистике» [9, с. 208].

Учитывая вышесказанное, надо отметить, что главная цель данной статьи дать полный обзор процессу заимствования английских слов тюркскими языками в целом, выявить самую динамичную и активную сферу языка при заимствовании новых слов.

Изложение основного материала исследования. Слова, которые полностью ассимилируются с языковыми законами и нормами тюркских языков быстро усваиваются и приживаются в данных языках. А другие либо заменяются новыми словами, созданными на базе языка реци- 
пиента, либо утрачивают свою актуальность. По данному поводу Л.В. Разумова пишет, что «Исходя из их знакового характера, можно говорить о заимствованиях фрормальных и семантических. Формальные заимствования заключаются в отражении в языке-реципиенте формальных свойств, которые заимствуемая языковая единица имеет в языке-доноре. $\mathrm{K}$ формальным заимствованиям относим:

- заимствования, не адаптированные фонетически, графрически и/или морфологически;

- заимствования, фонетически, графически и/или морфологически адаптированные в языкереципиенте;

- "мнимые англицизмы"» [5, с. 230].

«Заимствованные слова обычно приспосабливаются к фронетическим закономерностям принимающего языка» [8, с. 54]. В основном английские слова заимствуются с сохранением их звучания в английском языке. Например, klub (club), killer (killer), klininq (clearing), fayl (file), fləş kart (flash card), ləp top (lap top) и др. «Значительную часть английских заимствований составляют имена существительные. Морфологическое освоение иноязычной лексики, в частности существительных, начинается с приобретения ими категорий принадлежности, числа, падежа и оформления соответствующими формальными показателями» [8, с. 54].

«Важным следствием процесса заимствования является то, что сейчас английский язык призван выполнять не просто роль иностранного языка, а всё чаще выступает в качестве языка-базиса, на который ориентируются носители других языков при формировании конвенций электронного общения и, в некоторой мере, при концептуализации и категоризации виртуальной реальности» [2, с. 17].

В тюркских языках английские заимствования в основном встречаются в экономической лексике: ofşor - odшор, menecer - менеджер, управляющий, marketinq - маркетинг, defolt - дефолт, tender - тендер; в названиях бытовых устройств: toster - тостер, mikser - микcep, monitor - монитор, ləptop - ноутбук, planşet планшет, ayfon - айфрон и др. Например, если посмотреть на лексику современного турецкого литературного языка, то можно сказать, что многочисленную группу английских заимствований здесь составляют слова, связанные с молодежной модой, культурой, музыкой, кино, телевидением, рекламой и т. д. Например, star (star) - звезда (кино, театра); blucin (blue-jeans) - джинсы; blazer (blazer) - блейзер; bermuda (bermudas, bermuda shorts) - бермуды, шорты до колен; cin (gin) джинсы; medya (mass media) - средства массовой инфрормации; şov (show) - шоу, представление; kasting (casting) - распределение ролей; slogan лозунг и т.д. Как отмечает Л.В.Ахметшина, «одной из особенностей функщионирования ан- глийских заимствований периода 90-х гг. XX в. до наших дней является появление большого количества английских заимствований, относящихся к миру молодежной культуры: Вау!, бой-фрренд, драйв, йес, сури, хеппи бёрздей, римейк, хит, шоппинг, фрифрти-фридрти и т. д.» [1, с. 132]. Автор, исследуя заимствования в татарском языке, тоже отмечает, что в данном языке во всех сорерах встречаются очень много английских заимствований.

Исследуя английские заимствования в азербайджанском языке Н.А. Тагизаде отмечает, что здесь «есть достаточное количество англицизмов, которые используются в широком кругу и даже вошли в число слов общеупотребительных и уже не воспринимаются как иноязычные. Эти заимствования заняли прочное место в лексической системе Азербайджанского языка» [7, с. 32]. В качестве таких слов он перечисляет такие слова, как бюджет (budget), вокзал (vaux hall), вагон (wagon), вазелин (vaseline), бокс (box), клуб (club), фрутбол (football), юмор (humour), экспорт (export), фриниш (finish), трамвай (tramway), туннель (tunnel), турист (tourist), телефрон (telephone), рельс (rails), пиджак (pea-jacket), парк (park), магазин (magazine), кофре (coffee) и т.д. Но почему то автор не затрагивает то, что данные слова заимствованы азербайджанским языком посредством русского языка и практически подверглись ассимиляции по фонетическим и грамматическим признакам. Некоторые этих слов в современном азербайджанском языке стали заменятся другими заимствованными английскими словами. Например, сегодня вместо слово «магазин» в азербайджанском языке часто употребляется слово «маркет» (market) или «стор» (store). Надо отметить, что в современной эпохе развития азербайджанский язык, как и многие тюркские языки, при заимствовании английских слов не пользуется языком посредником, как это было до конца XX века. Развитие виртуального пространства и интернет услуг обеспечивает им прямое взаимодействие и обмен языковыми единицами с английским языком.

Выводы из данного исследования. Рассмотрев изложенные языковые фракты, можно сделать такой вывод, что, английские заимствования в тюркских языках, в основном, охватывают научную терминологию разных сфер.

В азербайджанском, татарском и др. тюркских языках, которые были в тесном контакте с русским языком, до конца XX века заимствовали английские лексические единицы посредством русского языка.

Научная терминология, лежащая почти целиком за пределами основного фронда турецкого языка, очень проницаема в отношении иноязычных заимствований и большую ее часть составляют термины иностранного происхождения.

\section{Список литературы:}

1. Ахметшина Л.В. Использование английской заимствованной лексики в современной татарской публищистике. Известия Российского государственного педагогического университета ил. А.И. Гериена. 2009. № 90. С. $131-135$.

2. Горбунова И.В. Процессы англизации в эпоху развития языка интернета. Бизнес образование в эконолике знаний. № 2. 2016. С. 13-18.

3. Мамедова Н.Я. Обогащение словарного состава турецкого литературного языка английскими заимствованиями. Ученые записки Таврического национального университета илени В.И. Вернадского. Серия: Филология. Социальные колмуникации. 2009. Т. 22 (61). № 3. С. 135-140. 
4. Махмудова Г.Ч. Процесс образования новых слов в тюркских языках в период независимости тюркоязычных государств. Вестник Волжского университета В.Н. Татищева. 2019. № 1. Том 1. С. 57-63.

5. Разумова Л.В. Проблема типологии английских заимствований. Научные ведолости Белгородского государственного университета. Серия: Гуланитарные науки. 2019. Т. 38. № 2. С. 227-235.

6. Сооронкулова Н.А. Английские заимствования в кыргызском языке. Причины заимствования. Вестник Кыркызско-Российского славянского университета. 2018. Том 18. № 1. С. 100-101.

7. Тагизаде Н.А. Семантическое освоение англицизмов в языке азербайджанской прессы. Ученье записки Таврического наиионального университета ил. В. И. Вернадского. Серия "Филология. Социальные колмуникаиии». 2009. Том 22 (61). № 3. С. 31-36.

8. Яруллина А.Г., Каюмова Г.И. Англицизмы и их освоение в Татарской языковой культуре (по материалам «Татарскойи энсиклопедии»). Вестник КАЗГУКИ. 2018. № 3. С. 53-57.

9. Evans V., Green M. Cognitive linguistics. An Introduction. Edinburgh: Edinburgh University Press, 2006.830 p.

10. Habibova K.A. Language policy in the virtual space. 1st International Scientific Conference "Modern Management Trends and the Digital Economy: from Regional Development to Global Economic Growth" (MTDE 2019) // Advances in Economics, Business and Management Research. 2020. Vol. 81. Pp. 789-792.

11. Johanson L. Code copying in Irano-Turkic. Language Sciences. 1998. Vol. 20. Pp. 325-337.

12. Levinson Y., Stephen C. Pragmatics. Cambridge Textbooks in Linguistics. Cambridge : Cambridge University Press., 1983. 420 p.

13. Teun A. van Dijk. Pragmatics of language and literature. Amsterdam : North Holland, 1976. 340 p.

14. Waterman J. A History of the German Language. Washington : University of Washington Press, 1976.120 p.

\section{References:}

1. Akhmetshina L.V. (2009). Ispol'zovanie anglijjskojj zaimstvovannojj leksiki v sovremennojj tatarskojj publicistike [The use of English borrowed vocabulary in modern Tatar journalism]. Izvestija Rossijjskogo gosudarstvennogo pedagogicheskogo universiteta im. A.I. Gercena, vol. 90, pp. 131-135.

2. Gorbunova I.V. (2016). Processy anglizacii v ehpokhu razvitija jazyka internet [Englishzation processes in the era of the development of the Internet language]. Biznes obrazovanie v ehkonomike znanijj, vol. 2, pp. 13-18.

3. Mamedova N.Ja. (2009). Obogashhenie slovarnogo sostava tureckogo literaturnogo jazyka anglijjskimi zaimstvovanijami [Enriching the vocabulary of the Turkish literary language with English borrowings]. Uchenye zapiski Tauricheskogo nacional'nogo universiteta imeni V.I. Vernadskogo. Serija: Filologija. Social'nye kommunikacii, vol. 22(61), no. 3, pp. 135-140.

4. Makhmudova G.Ch. (2019). Process obrazovanija novykh slov v tjurkskikh jazykakh v period nezavisimosti tjurkojazychnykh gosudarstv [The process of the formation of new words in the Turkic languages during the period of independence of the Turkic-speaking states]. Vestnik Volzhskogo universiteta V.N. Tatishheva, vol. 1, part 1, pp. 57-63.

5. Razumova L.V. (2019). Problema tipologii anglijjskikh zaimstvovanijj [The problem of typology of English borrowings]. Nauchnye vedomosti Belgorodskogo gosudarstvennogo universiteta. Serija: Gumanitarnye nauki, vol. 38, no. 2, pp. 227-235.

6. Sooronkulova N.A. (2018). Anglijskie zaimstvovanija v kyrkyzskom jazyke. Prichiny zaimstvovanija [English loanwords in the Kyrgyz language. Reasons for borrowing]. Vestnik Kyrkyzsko-Rossiyskoqo slavyanskoqo universiteta, vol. 18, no. 1, pp. 100-101.

7. Tagizade N.A. (2009). Semanticheskoe osvoenie anglicizmov v jazyke azerbajjdzhanskojj pressy [Semantic assimilation of Anglicisms in the language of the Azerbaijani press]. Uchenye zapiski Tavricheskogo nacional'nogo universiteta im. V. I. Vernadskogo. Serija "Filologija. Social'nye kommunikacii", vol. 22(61), no. 3, pp. 31-36.

8. Jarullina A.G., Kajumova G.I. (2018). Anglicizmy i ikh osvoenie v Tatarskojj jazykovojj kul'ture (po materialam «Tatarskojji ehnsiklopedii») [English borrowings and their development in the Tatar language culture (based on the materials of the "Tatar and Encyclopedia")]. Vestnik KAZGUKI, no. 3, pp. 53-57.

9. Evans V., Green M. (2006). Cognitive linguistics. An Introduction. Edinburgh: Edinburgh University Press, 830 p.

10. Habibova K.A. (2020). Language policy in the virtual space. 1st International Scientific Conference "Modern Management Trends and the Digital Economy: from Regional Development to Global Economic Growth" (MTDE 2019) // Advances in Economics, Business and Management Research, vol. 81, pp. 789-792.

11. Johanson L. (1998). Code copying in Irano-Turkic. Language Sciences, vol. 20, pp. 325-337.

12. Levinson Y., Stephen C. (1983). Pragmatics. Cambridge Textbooks in Linguistics. Cambridge: Cambridge University Press, 420 p.

13. Teun A. van Dijk (1976). Pragmatics of language and literature. Amsterdam: North Holland, 340 p.

14. Waterman J.A. (1976). History of the German Language. Washington: University of Washington Press, 120 p. 